\title{
Prevalence of Diabetes Mellitus and Metabolic Syndrome in Prostate Cancer Patients given Androgen Deprivation Therapy
}

\author{
Maria Luisa Cecilia Rivera-Arkoncel, ${ }^{1}$ Michael Sagun, ${ }^{2}$ Francis Raymond Arkoncel, ${ }^{2}$ \\ Cecilia Jimeno, ${ }^{1}$ Marie Carmela Lapitan, ${ }^{2}$ \\ ${ }^{1}$ Section of Endocrinology, Diabetes and Metabolism, Department of Medicine, University of the Philippines- Philippine General Hospital \\ ${ }^{2}$ Division of Urology, Department of Surgery, University of the Philippines- Philippine General Hospital
}

\begin{abstract}
Objective. To compare the prevalence of diabetes mellitus (DM) and metabolic syndrome (MetS) in prostate cancer patients with or without androgen deprivation therapy (ADT).

Methodology. This is a cross-sectional analytic study of prostate cancer patients from the Integrated Surgical Information System database of the Philippine General Hospital from 2004-2010. Patients who received either continuous monthly $\mathrm{GnRH}$ agonist injection for at least 6 months or underwent bilateral orchiectomy at least 6 months prior (ADT group) were compared to those who did not (non-ADT group). Patients with DM and MetS were identified using the American Diabetes Association Standards of Medical Care in Diabetes 2010 and IDF Definition of Metabolic Syndrome.
\end{abstract}

Results. The prevalence of DM in the ADT group is $42 \%$ and $19 \%$ in the non-ADT group ( $p=0.0460$ ). The probability of having DM is $2.17 x$ higher among prostate cancer patients who received ADT compared to those who did not. The prevalence of metabolic syndrome in the ADT and non-ADT group is $37 \%$ and $28 \%$, respectively $(p=0.4620)$.

Conclusions. Prostate cancer patients have become an important emerging population of medically at risk older men. Our study showed that the prevalence of DM is significantly higher among the ADT group, with a trend towards greater prevalence of metabolic syndrome in the same group. These men may benefit from closer monitoring for the development of these metabolic complications.

Key words: prostate cancer, diabetes mellitus, metabolic syndrome, androgen deprivation therapy

\section{INTRODUCTION}

Prostate cancer is the most common cancer among men, with a median age at diagnosis of 68 years. ${ }^{1}$ The incidence of prostate cancer has risen by $5-118 \%$ in Asian countries, with the highest rates noted in Rizal Province in the Philippines, although this is still much lower than those in the United States and many European countries. ${ }^{2}$ Data derived from two population-based cancer registries in the country, namely: the Department of Health-Rizal Cancer Registry and the Philippine Cancer Society Inc.-Manila Cancer Registry showed that from 1980 to 1995, prostate cancer has remained one of the leading cancers with note of increasing incidence rates (from $12.5 \%$ for 1980-82 to $19.3 \%$ in $1993-95) .^{3}$

Androgen deprivation therapy (ADT) is commonly used in the treatment of advanced, recurrent and metastatic prostate cancer. This is achieved surgically, with bilateral orchiectomy or medically, with luteinizing-hormone (LHRH) agonists. ${ }^{4}$ Although the use of ADT has resulted in improved survival for men with advanced prostate cancer, the resulting hypogonadism has adverse

e-ISSN 2308-118x

Printed in the Philippines

Copyright (C) 2014 by the JAFES

Received December 4, 2013. Accepted April 21, 2014. consequences. These include increased body mass index (BMI), decreased lean body mass, muscle strength and decreased bone density, diminished sexual function, increased incidence of diabetes mellitus and metabolic syndrome, and poorer quality of life compared with men who only underwent surgery and/or radiation therapy..$^{4-9}$ Recent reports showed that men receiving ADT have 25\% higher risk of incident coronary artery disease compared with non-ADT patients ${ }^{10}$ and that men on ADT for at least 1 year had a $20 \%$ higher risk of cardiovascular morbidity compared with non-ADT subjects. ${ }^{11}$ Metabolic alterations such as insulin resistance, diabetes mellitus and metabolic syndrome may be responsible for the increased cardiovascular mortality in these men. ${ }^{12}$

Review of published local literature reveals the absence of any data on the epidemiology of diabetes and metabolic syndrome among individuals with prostatic cancer, especially those who have undergone ADT. This study will provide a basis for recommending screening and monitoring for diabetes mellitus and other metabolic disorders in patients with prostate cancer for whom ADT is contemplated. 


\section{OBJECTIVES}

1. To compare the prevalence of diabetes mellitus $(\mathrm{DM})$ in prostate cancer patients with or without ADT

2. To compare the prevalence of metabolic syndrome (MetS) in prostate cancer patients with or without ADT

\section{METHODOLOGY}

\section{Design}

A cross-sectional analytical study was performed.

\section{Inclusion and Exclusion Criteria}

Identified were prostate cancer patients who received hormonal therapy (ADT group-continuous monthly LHRH agonist injection for at least 6 months or bilateral orchiectomy at least 6 months prior), and patients who did not receive hormonal therapy (non-ADT group) but underwent local treatment for prostate cancer (radical prostatectomy and/or radiotherapy). Patients with history of glucocorticoid use, thyroid disease, or cytotoxic chemotherapy were excluded.

\section{Methodology}

The Integrated Surgical Information System database of the Department of Surgery of the Philippine General Hospital from 2004-2010 was retrospectively reviewed. Eligible patients were contacted by telephone and were thoroughly advised regarding the benefits and risks of participating in the study. Interested patients were asked to come for a consultation where any further concerns were addressed. Informed consent was subsequently obtained.

Historical data gathered included the patients' age, smoking history, known comorbid conditions (diabetes mellitus, hypertension, dyslipidemia), family medical history, medications taken, date of orchiectomy or initiation of ADT for the ADT group, date of prostatectomy and/or radiation therapy for the non-ADT group. On physical examination, the resting blood pressure in the sitting position, height, weight, body mass index and waist circumference were determined and subsequently recorded. The patients were previously instructed to fast for at least 10 hours prior to consult. Venipuncture was performed to determine the fasting blood sugar, $\mathrm{HbA} 1 \mathrm{c}$, lipid profile (total cholesterol, triglycerides, HDL and LDL). A second blood extraction was done two hours after intake of a $75 \mathrm{gm}$ oral glucose load. Patients were diagnosed to have diabetes mellitus and metabolic syndrome using the American Diabetes Association Standards of Medical Care in Diabetes $2010^{13}$ and IDF Definition of Metabolic Syndrome, respectively. ${ }^{14}$ Diagnosed patients were referred to the Section of
Endocrinology, Diabetes and Metabolism of the Department of Medicine of the Philippine General Hospital and were treated according to international standards of care.

The mean and standard deviation of continuous data were described while categorical data were expressed as frequencies and percentages. The Fisher's exact point probability test and chi square test were used to compare the two groups and establish the association of the prevalence of DM and MetS with the groups. The ShapiroWilk test determined the normality of distribution. While most of the variables included in the investigation are categorical, it was found that the distribution is not normal. This was a basis to use the non-parametric test. Overall and age-adjusted prevalence of diabetes mellitus and metabolic syndrome in the two groups, as well as the $95 \%$ confidence interval for the true prevalence of diabetes mellitus and metabolic syndrome were computed. A p value $<0.05$ was considered significant.

The protocol of this study was reviewed and approved by the ethics committee of the Expanded Hospital Research Office of the Philippine General Hospital.

\section{RESULTS}

Seventy-four patients were included in the study: 38 were classified as belonging to the ADT group while the 36 patients were identified for the non-ADT group.

Prostate cancer patients under the ADT group are older, had higher systolic blood pressure, fasting blood glucose and mean triglyceride levels than those in the non-ADT group. (Table 1)

Table 2 shows the overall prevalence of pre-diabetes is $47 \%$. The overall prevalence of diabetes mellitus is $31 \%$ and the overall prevalence of metabolic syndrome is $32 \%$.

The probability of having diabetes mellitus is 2.17 times higher among prostate cancer patients belonging to the ADT group than prostate cancer patients belonging to the non-ADT group (p-value: 0.0460). For the age-specific prevalence ratio, it is highest at ages 60-69 years old, where the probability of having diabetes mellitus is. 3.67 times higher among patients belonging to the ADT group than patients in the non-ADT group (p-value: 0.0260).

The probability of having metabolic syndrome is 1.33 times higher among prostate cancer patients belonging to the ADT group than prostate cancer patients belonging to the non-ADT group (p-value: 0.4620 ). Specifically for the 60-69 age group, the prevalence ratio is highest at 3.67 which means that the risk of having metabolic syndrome is 3.67 times higher for patients belonging to the ADT group than patients in the non-ADT group. (p-value: 0.0260) 
Table 1. Demographic, clinical and biochemical profile of prostate cancer patients

\begin{tabular}{|c|c|c|}
\hline Characteristic & $\begin{array}{l}\text { ADT group } \\
(n=38)\end{array}$ & $\begin{array}{c}\text { Non-ADT } \\
\text { group }(n=36)\end{array}$ \\
\hline \multicolumn{3}{|l|}{ Age, years } \\
\hline Mean, SD & $69.61,7.51$ & $64.58,6.43$ \\
\hline Smokers (\%) & $17(44.74 \%)$ & $19(52.78 \%)$ \\
\hline \multicolumn{3}{|l|}{ Duration of ADT (months) } \\
\hline Mean, SD & $16.61,17.11$ & - \\
\hline Previously diagnosed DM (\%) & $4(10.53 \%)$ & $1(2.78 \%)$ \\
\hline Hypertension (\%) & $14(36.84 \%)$ & $14(38.89 \%)$ \\
\hline On statin therapy(\%) & $4(10.53 \%)$ & $1(2.78 \%)$ \\
\hline \multicolumn{3}{|l|}{ Weight (kg) } \\
\hline Mean, SD & $62.94,11.36$ & $65.42,9.15$ \\
\hline \multicolumn{3}{|l|}{ Height (m) } \\
\hline Mean, SD & $1.65,0.05$ & $1.66,0.07$ \\
\hline \multicolumn{3}{|l|}{ Waist circumference $(\mathrm{cm})$} \\
\hline Mean, SD & $88.28,10.52$ & $90.29,7.84$ \\
\hline \multicolumn{3}{|l|}{$B M I(k g / m 2)$} \\
\hline Mean, SD & $23.02,3.35$ & $23.16,5.41$ \\
\hline \multicolumn{3}{|l|}{ Blood pressure } \\
\hline \multicolumn{3}{|l|}{ Systolic $(\mathrm{mmHg})$} \\
\hline Mean, SD & $136.05,17.79$ & $127.5,14.02$ \\
\hline \multicolumn{3}{|l|}{ Diastolic $(\mathrm{mmHg})$} \\
\hline Mean, SD & $80.00,6.58$ & $79.17,7.70$ \\
\hline \multicolumn{3}{|l|}{ FBS $(\mathrm{mmol} / \mathrm{L})$} \\
\hline Mean, SD & $6.88,3.50$ & $5.13,0.67$ \\
\hline \multicolumn{3}{|l|}{ HbA1c (\%) } \\
\hline Mean, SD & $6.31,1.86$ & $5.70,0.60$ \\
\hline \multicolumn{3}{|l|}{$2 \mathrm{hr}$ Glucose after $75 \mathrm{~g}$ OGTT } \\
\hline Mean, SD & $10.16,6.20$ & $9.00,3.39$ \\
\hline \multicolumn{3}{|l|}{ Lipid Profile } \\
\hline \multicolumn{3}{|l|}{$H D L(\mathrm{mmol} / \mathrm{L})$} \\
\hline Mean, SD & $1.24,0.33$ & $1.14,0.38$ \\
\hline \multicolumn{3}{|l|}{$L D L(\mathrm{mmol} / \mathrm{L})$} \\
\hline Mean, SD & $3.17,1.20$ & $3.16,1.02$ \\
\hline \multicolumn{3}{|l|}{ Triglycerides (mmol/L) } \\
\hline Mean, SD & $1.66,0.83$ & $1.26,0.75$ \\
\hline \multicolumn{3}{|l|}{ Total Cholesterol (mmol/L) } \\
\hline Mean, SD & $5.17,1.35$ & $4.87,1.36$ \\
\hline
\end{tabular}

Table 2. Overall prevalence proportion of diabetes mellitus and metabolic syndrome among prostate cancer patients

\begin{tabular}{lc}
\hline \multicolumn{1}{c}{ Condition } & $\begin{array}{c}\text { Overall Prevalence Proportion } \\
(\mathbf{n}=\mathbf{7 4})\end{array}$ \\
\hline Pre-diabetes & $35(47 \%)$ \\
Diabetes Mellitus & $23(31 \%)$ \\
Metabolic Syndrome & $24(32 \%)$ \\
\hline
\end{tabular}

Table 3. Distribution of patients with prostate cancer according to age and prevalence of diabetes mellitus

\begin{tabular}{lllllll}
\multirow{2}{*}{$\begin{array}{c}\text { Age } \\
\text { groups }\end{array}$} & \multicolumn{2}{c}{ ADT group } & \multicolumn{2}{c}{$\begin{array}{c}\text { Non-ADT } \\
\text { group }\end{array}$} & $\begin{array}{c}\text { Prevalence } \\
\text { ratio }\end{array}$ & P-value \\
\cline { 2 - 7 } & $\mathbf{n}$ & $\begin{array}{c}\text { Prevalence } \\
\text { of DM }\end{array}$ & $\mathbf{n}$ & $\begin{array}{c}\text { Prevalence } \\
\text { of DM }\end{array}$ & & \\
\hline Overall & 38 & $16(42 \%)$ & 36 & $7(19 \%)$ & 2.17 & $\mathbf{0 . 0 4 6 0}$ \\
$40-49$ years & 0 & 0 & 1 & $0(0 \%)$ & - & - \\
$50-59$ years & 4 & $2(50 \%)$ & 5 & $2(40 \%)$ & 1.25 & 1.0000 \\
$60-69$ years & 14 & $7(50 \%)$ & 22 & $3(14 \%)$ & 3.67 & $\mathbf{0 . 0 2 6 0}$ \\
$70-79$ years & 17 & $5(29 \%)$ & 8 & $2(25 \%)$ & 1.18 & 1.0000 \\
$>80$ years & 3 & $2(67 \%)$ & 0 & 0 & - & - \\
\hline
\end{tabular}

For patients with metabolic syndrome, the breakdown of each component is in Table 5. Elevated blood sugar is the most common component of the metabolic syndrome followed by elevated blood pressure among the ADT group. Comparing the ADT and non-ADT groups, the prevalence proportions are comparable except for high fasting plasma glucose (p-value: 0.0020 ). The probability of having high plasma glucose is 3.10 times greater among the ADT group than in the non-ADT group for patients with metabolic syndrome.

\section{DISCUSSION}

The reported 5-year relative survival rate for all stages of prostate cancer is $98.8 \%$ and for those who present with metastatic disease, almost $10 \%$ live 10 years beyond diagnosis. ${ }^{15,16}$ Because of this improvement in survival rates, prostate cancer patients have become an important emerging population of medically at risk older men. Therefore, it has become important to closely examine side effects of treatment which can potentially contribute to other co-morbidities.

Treatment modalities for prostate cancer include surgery, radiotherapy and ADT. ADT is accomplished through either bilateral orchiectomy or gonadotropin-releasing hormone $(\mathrm{GnRH})$ agonist injection causing

Table 4. Prevalence of metabolic syndrome for the study groups

\begin{tabular}{|c|c|c|c|c|c|c|}
\hline & $\mathbf{n}$ & $\begin{array}{c}\text { Prevalence Proportion for } \\
\text { the ADT group }\end{array}$ & $\mathbf{n}$ & $\begin{array}{c}\text { Prevalence Proportion for the } \\
\text { non-ADT group }\end{array}$ & $\begin{array}{c}\text { Prevalence } \\
\text { Ratio }\end{array}$ & P-value \\
\hline Overall & 38 & $14(37 \%)$ & 36 & $10(28 \%)$ & 1.33 & 0.4620 \\
\hline $40-49$ years & 0 & 0 & 1 & $1(100 \%)$ & - & - \\
\hline $60-69$ years & 14 & $7(50 \%)$ & 22 & $3(14 \%)$ & 3.67 & 0.0260 \\
\hline $70-79$ years & 17 & $3(18 \%)$ & 8 & $4(50 \%)$ & 0.35 & 0.1560 \\
\hline$>80$ years & 3 & $1(33 \%)$ & 0 & $0(0 \%)$ & - & - \\
\hline
\end{tabular}

Table 5. Metabolic syndrome components [for patients who have metabolic syndrome]

\begin{tabular}{|c|c|c|c|c|c|}
\hline $\begin{array}{c}\text { Metabolic Syndrome } \\
\text { Components }\end{array}$ & Overall & $\begin{array}{l}\text { Prevalence proportion for } \\
\text { the ADT Group }(n=14)\end{array}$ & $\begin{array}{l}\text { Prevalence proportion for } \\
\text { the Non-ADT group }(n=10)\end{array}$ & Ratio & P-value \\
\hline Elevated triglycerides & $11(46 \%)$ & $6(43 \%)$ & $5(50 \%)$ & 0.86 & 1.0000 \\
\hline Raised systolic BP & $17(71 \%)$ & $11(79 \%)$ & $6(60 \%)$ & 1.31 & 0.3930 \\
\hline Raised diastolic BP & $8(33 \%)$ & $5(36 \%)$ & $3(30 \%)$ & 1.19 & 1.0000 \\
\hline Raised fasting plasma glucose & $16(67 \%)$ & $13(93 \%)$ & $3(30 \%)$ & 3.10 & 0.0020 \\
\hline
\end{tabular}


hypogonadism. Using ADT has proven benefit in improving over-all survival in the following patients: a) for locally advanced or high risk non-metastatic disease (in combination with external beam radiation therapy), b) for metastatic disease (as primary therapy) and c) with nodal metastases after prostatectomy and pelvic lymphadenectomy (as adjuvant therapy). ${ }^{17-22}$

In the United States, GnRH agonists are currently favored over orchiectomy because of their reversibility, ease of administration and patient acceptability. Because of this, there is a rising prevalence of $\mathrm{GnRH}$ agonist treatment reported. ${ }^{23,24}$ This is in contrast to our study where most of the patients belonging to the ADT group underwent orchiectomy (29 out of 38). The greater cost of continuous $\mathrm{GnRH}$ agonist injections compared to a single, simple operative procedure may account for this difference.

ADT causes hypogonadism with the aim to achieve serum testosterone levels as low as possible. Two populationbased studies have demonstrated that a lower than normal level of serum testosterone is an independent risk factor for diabetes and metabolic syndrome..$^{25,26}$

Based on this premise, the drastic reduction in serum testosterone associated with ADT causes several adverse changes in body composition, lipid profile and insulin sensitivity.

\section{Body composition}

Androgens promote lean body mass over fat mass. Conversely, ADT causes a shift in body composition. ${ }^{15}$ Several studies have demonstrated that there is loss of lean body mass with concurrent gain in fat body mass associated with ADT. ${ }^{6,27-29}$ There is also associated weight gain of $\sim 2 \%$ in 12 months. ${ }^{27,28,30}$ Another study also showed mean weight gain of $2.2 \mathrm{~kg}$ that occurred primarily in the first year of therapy. ${ }^{31}$

\section{Lipid profile}

Recent epidemiological research suggests that low serum testosterone levels are associated with an abnormal lipid profile. $^{32}$ In addition, studies using testosterone replacement for treatment of hypogonadal men improved the lipid profile. ${ }^{33}$ Several cross-sectional and prospective trials have evaluated the changes in lipid profile due to ADT. Serum triglycerides increase by about $26 \%$ in the first 3-6 months of treatment and total cholesterol by about $7-10 \%$ in the first 3-12 months of treatment. Serum HDL rose by $8-20 \%$ in the first 3-12 months of treatment. ${ }^{27,34,35}$ Serum HDL decreased by $\sim 5 \%$ in 12 months in one study. ${ }^{36}$ There was no change in serum LDL in 3-6 months of therapy. ${ }^{34,35}$ However, there was one study which showed a rise in LDL of $7 \%$ in the first 3 months. ${ }^{27}$ Our study demonstrated that patients on ADT have higher level of serum triglycerides with mean level of $1.66 \mathrm{mmol} / \mathrm{L}$ (SD 0.83 ) compared with the non-ADT group.
Dyslipidemia is a known risk factor for cardiovascular disease. There is a strong, continuous, graded relationship between serum cholesterol and cardiovascular mortality. 37,38 Thus, strategies to monitor and treat this group of patients should be studied.

\section{Insulin resistance and diabetes}

Prospective data showed that ADT use causes decreased insulin sensitivity. Fasting insulin rose by $26-65 \%$ while the serum glucose did not significantly change in the first 3 months. ${ }^{6,34,39}$ Insulin sensitivity index also decreased by $13 \%$ in 12 weeks. ${ }^{39}$

Insulin resistance is an independent risk factor for diabetes and cardiovascular disease. ${ }^{40}$ In the general population, diabetes is a major health concern given its increasing prevalence, its associated complications causing morbidity and mortality. Globally, there were already approximately 140 million people with diabetes in 1998. The World Health Organization (WHO) has projected that this figure will rise to 300 million by the year $2025 .^{41}$ Even prior to initiation of ADT, a considerable proportion of men already have diabetes or prediabetes.

Two large population based studies showed that ADT is associated with greater incidence of diabetes. The first reported an adjusted hazard ratio for incident diabetes of $1.44(p<0.001)$ for men treated with GnRH agonists and 1.34 ( $p<0.001)$ for those who underwent orchiectomy. ${ }^{10}$ The second reported an adjusted hazard ratio for a new diagnosis of diabetes of 1.16 (95\% CI 1.11-1.12). This included nearly 20,000 men $\geq 66$ years old treated with either bilateral orchiectomy or 6 months or more of $\mathrm{GnRH}$ agonist. $^{8}$

Some studies have evaluated glucose metabolism in prostate cancer patients. Smith et.al., in 2001 and Dockery et.al., in 2003 showed that prostate cancer patients receiving ADT after 3 months of treatment did not show a significant change in plasma glucose levels but demonstrated a $63 \%$ rise in insulin levels. ${ }^{6,34}$ A 12 - week prospective study by Smith et.al., in 2006 reported similar results with increase in insulin level in ADT group $(p=0.04)$ without significant change in glucose levels. In addition, results showed decreased insulin sensitivity index $(\mathrm{P}=0.02) .{ }^{39}$ In 2006, a cross-sectional study by Basaria et al., showed that after a longer period of ADT treatment (12-101 months), fasting glucose and insulin levels were significantly higher $(p=0.002)$ compared with non-ADT group and control group. Patients in the ADT group were also more insulin resistant as shown by HOMA-IR value $(\mathrm{p}<0.001)$. The prevalence of diabetes in the ADT group (by using FBS criteria) was $44 \%$ compared with $12 \%$ in the non-ADT group and $11 \%$ in the control group. ${ }^{5}$ These findings may suggest that insulin resistance develops within a few months after receiving ADT, and eventually, with prolonged treatment, hyperglycemia and overt diabetes develop. 
Our study showed that fasting blood glucose is significantly higher in the ADT than in the non-ADT group [p-value: 0.0044]. The higher HbA1c in the ADT group (ADT group: $6.31 \%$ vs non-ADT group: $5.7 \%$ ) approached statistical significance $(p=0.0670)$. The prevalence of diabetes is $42 \%$ in the ADT group and $19 \%$ in the non-ADT group, which is comparable to the study of Basaria et al. ${ }^{5}$

\section{Metabolic syndrome}

Metabolic syndrome as defined by IDF consists of: central obesity: waist circumference $\geq 90 \mathrm{~cm}$ (specific for South Asians males), plus any two of the following four factors: raised trigycerides $(\geq 1.7 \mathrm{mmol} / \mathrm{L}$ or specific treatment for this lipid abnormality), reduced HDL cholesterol $(<1.03$ $\mathrm{mmol} / \mathrm{L}$ or specific treatment for this lipid abnormality), raised blood pressure (systolic $\mathrm{BP} \geq 130$ or diastolic $\mathrm{BP} \geq 85$ $\mathrm{mm} \mathrm{Hg}$ or treatment of previously diagnosed hypertension), and raised fasting plasma glucose (FPG $\geq 5.6$ $\mathrm{mmol} / \mathrm{L}$ ), or previously diagnosed type 2 diabetes. It has received substantial interest in recent years because of its association with an increased risk of cardiovascular disease. ${ }^{14}$

Recently, low testosterone and sex hormone-binding globulin (SHBG) levels have been identified as independent risk factors in the development of metabolic syndrome. There are studies that reported that men with low testosterone levels have higher prevalence of metabolic syndrome. ${ }^{25,42}$ Patients with prostate cancer undergoing ADT became hypogonadal and were found to have higher risk for developing metabolic syndrome as well as cardiovascular risks. ${ }^{43}$ In a cross-sectional study done by Braga-Bassaria et al, metabolic syndrome was more prevalent in prostate cancer patients on ADT $(55 \%)$ compared with men in the non-ADT $(22 \%)$ and control group (20\%). ${ }^{4}$ Our study revealed a prevalence of $37 \%$ in the ADT group compared with $28 \%$ in the non-ADT group with a prevalence ratio of 1.33 .

Our study has some limitations. First, this was a crosssectional study, and we suggest prospective studies in this group of patients. Second, the fasting insulin levels and HOMA-IR to check for insulin resistance were not measured. Third, measurement of serum testosterone, SHBG and dihydroepiandrosterone-sulfate (DHEA-S) to check for severity of hypogonadism in association with metabolic profile would have been ideal. Lastly, an inclusion of age-matched controls would have been helpful to account for influence of age on the development of diabetes and metabolic syndrome.

It has been recognized for several years that men with prostate cancer have higher cardiovascular mortality. ${ }^{44}$ Because of the consistent data showing the link between prostate cancer patients on androgen deprivation therapy and multiple risk factors which include diabetes, dyslipidemia and metabolic syndrome, it is imperative that strategies in terms of screening, monitoring, treatment, counseling and follow-up be formulated.

\section{CONCLUSION}

In conclusion, the prevalence of diabetes mellitus and metabolic syndrome is higher in prostate cancer patients on androgen deprivation therapy compared with prostate cancer patients who did not undergo ADT. These metabolic complications may account for the higher risk for cardiovascular mortality observed in this group of patients. These men may benefit from counseling, screening and closer monitoring for development of these metabolic complications. Larger, prospective studies in this group of patients are recommended.

\section{Acknowledgments}

To the Philippine Society for the Study of Aging Male (PhiSSAM) and Philippine Urological Association (PUA) for their research grants.

\section{References}

1. Surveillance Epidemiology and End Results. SEER Stat Fact Sheets. Prostate Cancer. 2010 [January 1,2011]; Available from: http://seer.cancer.gov/statfacts/html/prost.html.

2. Hong Gee S, Christopher WSC. Changing demography of prostate cancer in Asia. European Journal of Cancer (Oxford, England : 1990). 2005;41(6):834-45.

3. Ngelangel CA, Wang EH. Cancer and the Philippine Cancer Control Program. Jpn J Clin Oncol. 2002 Mar;32 Suppl:S52-61.

4. Braga-Basaria M, Dobs AS, Muller DC, Carducci MA, John M, Egan J et al. Metabolic syndrome in men with prostate cancer undergoing long-term androgen-deprivation therapy. J Clin Oncol. 2006 Aug 20;24(24):3979-83.

5. Basaria S, Muller DC, Carducci MA, Egan J, Dobs AS. Hyperglycemia and insulin resistance in men with prostate carcinoma who receive androgen-deprivation therapy. Cancer. 2006 Feb 1;106(3):581-8.

6. Smith JC, Bennett S, Evans LM, Kynaston HG, Parmar M, Mason MD et al. The effects of induced hypogonadism on arterial stiffness, body composition and metabolic parameters in males with prostate cancer. J Clin Endocrinol Metab. 2001 Sep;86(9):4261-7.

7. Lage MJ, Barber BL, Markus RA. Association between androgendeprivation therapy and incidence of diabetes among males with prostate cancer. Urology. 2007 Dec;70(6):1104-8.

8. Alibhai SM, Duong-Hua M, Sutradhar R, Fleshner NE, Warde P, Cheung $\mathrm{AM}$, et al. Impact of androgen deprivation therapy on cardiovascular disease and diabetes. J Clin Oncol. 2009 Jul 20;27(21):3452-8

9. Basaria S, Lieb J, 2nd, Tang AM, DeWeese T, Carducci M, Eisenberger $\mathrm{M}$, et al. Long-term effects of androgen deprivation therapy in prostate cancer patients. Clin Endocrinol (Oxf). 2002 Jun;56(6):779-86.

10. Keating NL, O'Malley AJ, Smith MR. Diabetes and cardiovascular disease during androgen deprivation therapy for prostate cancer. J Clin Oncol. 2006 Sep 20;24(27):4448-56.

11. Saigal CS, Gore JL, Krupski TL, Hanley J, Schonlau M, Litwin MS. Androgen deprivation therapy increases cardiovascular morbidity in men with prostate cancer. Cancer. 2007 Oct 1;110(7):1493-500.

12. Basaria S. Androgen deprivation therapy, insulin resistance, and cardiovascular mortality: An inconvenient truth. J Androl 2008 SepOct;29(5):534-9.

13. Standards of medical care in diabetes--2010. Diabetes Care. Jan;33 Suppl 1:S11-61.

14. The International Diabetes Federation Worldwide Definition of the Metabolic Syndrome. 2006.

15. Saylor PJ, Smith MR. Adverse effects of androgen deprivation therapy: Defining the problem and promoting health among men with prostate cancer. J Natl Compr Canc Netw. Feb;8(2):211-23.

16. Tangen CM, Faulkner JR, Crawford ED, Thompson IM, Hirano D, Eisenberger $\mathrm{M}$, et al. Ten-year survival in patients with metastatic prostate cancer. Clin Prostate Cancer. 2003 Jun;2(1):41-5. 
17. Bolla M, Collette L, Blank L, Warde P, Dubois JB, Mirimanoff RO, et al. Long-term results with immediate androgen suppression and external irradiation in patients with locally advanced prostate cancer (an EORTC study): A phase III randomised trial. Lancet. $2002 \mathrm{Jul}$ 13;360(9327):103-6.

18. D'Amico AV, Manola J, Loffredo M, Renshaw AA, DellaCroce A, Kantoff PW. 6-month androgen suppression plus radiation therapy vs radiation therapy alone for patients with clinically localized prostate cancer: A randomized controlled trial. JAMA. 2004 Aug 18;292(7):821-7.

19. Leuprolide versus diethylstilbestrol for metastatic prostate cancer. The Leuprolide Study Group. N Engl J Med. 1984 Nov 15;311(20):1281-6.

20. Vogelzang NJ, Chodak GW, Soloway MS, Block NL, Schellhammer $\mathrm{PF}$, Smith JA, Jr., et al. Goserelin versus orchiectomy in the treatment of advanced prostate cancer: Final results of a randomized trial. Zoladex Prostate Study Group. Urology. 1995 Aug;46(2):220-6.

21. Walsh PC. Immediate versus deferred treatment for advanced prostatic cancer: Initial results of the Medical Research Council trial. The Medical Research Council Prostate Cancer Working Party Investigators Group. J Urol. 1997 Oct;158(4):1623-4.

22. Messing EM, Manola J, Yao J, Kiernan M, Crawford D, Wilding G, et al. Immediate versus deferred androgen deprivation treatment in patients with node-positive prostate cancer after radical prostatectomy and pelvic lymphadenectomy. Lancet Oncol. 2006 Jun;7(6):472-9.

23. Barry MJ, Delorenzo MA, Walker-Corkery ES, Lucas FL, Wennberg DC. The rising prevalence of androgen deprivation among older American men since the advent of prostate-specific antigen testing: A population-based cohort study. BJU Int. 2006 Nov;98(5):973-8.

24. Shahinian VB, Kuo YF, Freeman JL, Orihuela E, Goodwin JS. Increasing use of gonadotropin-releasing hormone agonists for the treatment of localized prostate carcinoma. Cancer. 2005 Apr 15;103(8):1615-24

25. Muller M, Grobbee DE, den Tonkelaar I, Lamberts SW, van der Schouw YT. Endogenous sex hormones and metabolic syndrome in aging men. J Clin Endocrinol Metab. 2005 May;90(5):2618-23.

26. Haffner SM, Shaten J, Stern MP, Smith GD, Kuller L. Low levels of sex hormone-binding globulin and testosterone predict the development of non-insulin-dependent diabetes mellitus in men. MRFIT Research Group. Multiple Risk Factor Intervention Trial. Am J Epidemiol. 1996 May 1;143(9):889-97.

27. Smith MR, Finkelstein JS, McGovern FJ, Zietman AL, Fallon MA, Schoenfeld DA, et al. Changes in body composition during androgen deprivation therapy for prostate cancer. J Clin Endocrinol Metab. 2002 Feb;87(2):599-603.

28. Smith MR. Changes in fat and lean body mass during androgendeprivation therapy for prostate cancer. Urology. 2004 Apr;63(4):7425.

29. Smith MR, Lee H, McGovern F, Fallon MA, Goode M, Zietman AL, et al. Metabolic changes during gonadotropin-releasing hormone agonist therapy for prostate cancer: Differences from the classic metabolic syndrome. Cancer. 2008 May 15;112(10):2188-94.

30. Tayek JA, Heber D, Byerley LO, Steiner B, Rajfer J, Swerdloff RS. Nutritional and metabolic effects of gonadotropin-releasing hormone agonist treatment for prostate cancer. Metabolism. 1990 Dec;39(12):1314-9.
31. Kim HS, Moreira DM, Smith MR, Presti JC, Jr., Aronson WJ, Terris $\mathrm{MK}$, et al. A natural history of weight change in men with prostate cancer on androgen-deprivation therapy (ADT): Results from the Shared Equal Access Regional Cancer Hospital (SEARCH) database. BJU Int. Sep 22.

32. Haffner SM, Mykkanen L, Valdez RA, Katz MS. Relationship of sex hormones to lipids and lipoproteins in nondiabetic men. J Clin Endocrinol Metab. 1993 Dec;77(6):1610-5.

33. Malkin CJ, Pugh PJ, Jones RD, Kapoor D, Channer KS, Jones TH. The effect of testosterone replacement on endogenous inflammatory cytokines and lipid profiles in hypogonadal men. J Clin Endocrinol Metab. 2004 Jul;89(7):3313-8.

34. Dockery F, Bulpitt CJ, Agarwal S, Donaldson M, Rajkumar C. Testosterone suppression in men with prostate cancer leads to an increase in arterial stiffness and hyperinsulinaemia. Clin Sci (Lond). 2003 Feb;104(2):195-201.

35. Eri LM, Urdal P, Bechensteen AG. Effects of the luteinizing hormonereleasing hormone agonist leuprolide on lipoproteins, fibrinogen and plasminogen activator inhibitor in patients with benign prostatic hyperplasia. J Urol. 1995 Jul;154(1):100-4.

36. Smith MR, Malkowicz SB, Chu F, Forrest J, Sieber P, Barnette KG, et al. Toremifene improves lipid profiles in men receiving androgendeprivation therapy for prostate cancer: Interim analysis of a multicenter phase III study. J Clin Oncol. 2008 Apr 10;26(11):1824-9.

37. Lewington S, Whitlock G, Clarke R, Sherliker P, Emberson J, Halsey J, et al. Blood cholesterol and vascular mortality by age, sex, and blood pressure: A meta-analysis of individual data from 61 prospective studies with 55,000 vascular deaths. Lancet. 2007 Dec 1;370(9602):1829-39.

38. Stamler J, Wentworth D, Neaton JD. Is relationship between serum cholesterol and risk of premature death from coronary heart disease continuous and graded? Findings in 356,222 primary screenees of the Multiple Risk Factor Intervention Trial (MRFIT). JAMA. 1986 Nov 28;256(20):2823-8.

39. Smith MR, Lee H, Nathan DM. Insulin sensitivity during combined androgen blockade for prostate cancer. J Clin Endocrinol Metab. 2006 Apr;91(4):1305-8.

40. Despres JP, Lamarche B, Mauriege P, Cantin B, Dagenais GR, Moorjani S, et al. Hyperinsulinemia as an independent risk factor for ischemic heart disease. N Engl J Med. 1996 Apr 11;334(15):952-7.

41. Cockram CS. The epidemiology of diabetes mellitus in the AsiaPacific region. Hong Kong Med J. 2000 Mar;6(1):43-52.

42. Laaksonen DE, Niskanen L, Punnonen K, Nyyssonen K, Tuomainen TP, Valkonen VP, et al. Testosterone and sex hormone-binding globulin predict the metabolic syndrome and diabetes in middle-aged men. Diabetes Care. 2004 May;27(5):1036-41.

43. D'Amico AV DJ, Crook J, Chen MH, Goldhaber SZ, Lamb DS, Joseph D, Tai KH, Malone S, Ludgate C, Steigler A, Kantoff PW. Influence of androgen suppression therapy for prostate cancer on the frequency and timing of fatal myocardial infarction. J Clin Oncol. 2007;25:2420-5.

44. Shahani S, Braga-Basaria M, Basaria S. Androgen Deprivation Therapy in Prostate Cancer and Metabolic Risk for Atherosclerosis. J Clin Endocrinol Metab. June 1, 2008;93(6):2042-9.

Articles and any other material published in the JAFES represent the work of the author(s) and should not be construed to reflect the opinions of the Editors or the Publisher. Authors are required to accomplish, sign and submit scanned copies of the JAFES Declaration: that the article represents original material, that is not being considered for publication or has not been published or accepted for publication elsewhere. Consent forms, as appropriate, have been secured for the publication of information about patients; otherwise, authors declared that all means have been exhausted for securing such consent. The authors have signed disclosures that there are no financial or other relationships that might lead to a conflict of interest. All authors are required to submit Authorship Certifications that the manuscript has been read and approved by all authors, and that the requirements for authorship have been met by each author. 